\title{
First Report of Microcystins in Cyanobacteria Microcystis sp. Isolated from Dianchi Lake, China*
}

\author{
ZHAO Yijun ${ }^{1}$, WANG Xu ${ }^{1}$,WU Hongyan ${ }^{1}$ \\ CHENG Kai ${ }^{1}$, LI Yuyuan ${ }^{1}$ and LIU Yongding ${ }^{2}$ \\ ${ }^{1}$ College of Life Science, Central China Normal University, Wuhan 430079, China \\ ${ }^{2}$ Institute of Hydrobiology, CAS, Wuhan 430072, China
}

\begin{abstract}
Isolates of Microcystis blooms collected from Dianchi Lake of South-western China in different seasons were tested by mouse bioassays. The $L D_{50}$ of the microcystis isolates corresponding M. wesenbergii, M.viridis and M. aeruginosa were $221 \mathrm{mg} \cdot \mathrm{kg}^{-1}, 188 \mathrm{mg} \cdot \mathrm{kg}^{-1}$, and 198 $\mathrm{mg} \cdot \mathrm{kg}^{-1}$ respectively. The cells of the three samples contained hepatotoxins or microcystins. The $H P L C$ (high performance liquid chromatography) analysis showed that all the three Microcystis species contained microcystin LR. In addition, M. wesenbergii contained microcystin RR, M. viridis contained microcystinYR, $M$. aeruginosa contained both microcystin $R R$ and $Y R$. The results suggested that in different seasons the toxins which were produced by the dominating Microcystis species were fluctuent with regard to the composition and content of the toxins and consenquently were obvious factors that aroused the water quality to decrease and change.
\end{abstract}

Keywords: Microcystis, microcystin, HPLC

\section{Introduction}

Blooms of cyanobacteria (blue-green algae) occur in eutrophicated lakes, ponds and rivers all over the world (Carmichael, 1992). A lot of species and strains of blue-green algae (cyanobacteria) forming blooms produce potent hepatotoxins or neurotoxins which are responsible for the death of wild and domestic animals consuming water contaminated with bloom (Schwimmer and Schwimmer, 1968; Tsuji, et al., 1994). Microcystis, Oscillatoria, Anabaena, Aphanizomenon, Nostoc and Nodularia produced these lethal toxins (Elleman et al. 1978; Botes et al., 1982; Watanabe, et al., 1989; Harada, et al., 1991). The colonial species Microcystis aeruginosa is the most common hepatotoxic cyanobacterium in eutrophic freshwaters (Carmichael, 1992).

Cyanobacterial heptotoxic cyclic heptapeptides are well known as microcystins possessing the general structure cyclo(-D-Ala-X-D-MeAsp-Z-Adda-D-Glu-Mdha-), where X and Z are variable L-amino acids, D-MeAsp is D-erythro- $\beta$-methylasparetic acid, and Mdha is N-methy-

\footnotetext{
'Received 1997-02-25; accepted 1998-03-27.
} 
ldehydroalanine (Carmichael, et al., 1988). More than 50 microcystins have been isolated from cyanobacteria (blue-green algae), such as a coccoid Microcystis and filamentous Anabaena, Nostoc, and Oscillatoria strains (Carmichael, 1988, 1992; Harada, et al; 1991, Sivonen, et al, 1992 a,b). Species and strains of Microcystis produce more than 40 types of related cyclic peptides called microcystins (Sivonen, et al., 1992). The toxins also inhibit protein phosphatases 1 and $2 \mathrm{~A}$ in a similar manner to akadaic acid and have a tumor-promoting activity in rat liver (NishiwakiMatsushima, et al., 1992). Microcystins as liver tumor promoters would threaten human health.

Eutrophication of Dianchi Lake in South-western China has resulted in massive increases of algae, often dominated and successed by the cyanobacteria $M$. wesenbergii, $M$. viridis and $M$. aeruginosa in different seasons of the year (Zhao Yijun, et al., 1996). This problem becomes intensified due to the lake's environmental characteristics necessary for cyanobacterial growth during the entire year. These include high light intensity, high nutrient concentrations, water temperatures between 15 to $30^{\circ} \mathrm{C}$ and little water movement.

Several analytical methods have been established for microcystins in cells of cyanobacteria, but high performance liquid chromatography (HPLC) is used most widespreadly (Brooks and Codd, 1986; Dierstein, et al., 1988). We reported the toxic $M$. wesenbergii first found in Taihu Lake of South-eastern China (He Jiawan, et al., 1996). In order to understand the occurrence and toxin production by the cyanobacteria blooms that were found in Dianchi Lake, we used the HPLC to work on the isolation, purification and characterization of microcystins from the Microcystis species dominating alternatively in different seasons of the year. In this paper we report the HPLC analytical results of microcystins in three Microcystis species including a new Chinese toxic cyanobacterium $-M$. viridis isolated from Dianchi Lake which were found to produce microcystins.

\section{Materials and methods}

\subsection{Cultures}

$M$. wesenbeigii, $M$. viridis and $M$. aeruginosa were isolated from bloom samples collected in Dianchi Lake in Octorber 1995, January 1996 and June 1996 seperately. The concentrations of $M$. wesenbeigii, $M$. viridis and $M$. aeruginosa were about $90 \%, 65 \%$ and $80 \%$ of the overal cyanobacteria respectively. Cells growing under optimatic conditions were harvested in the late exponential phase, washed, concentrated by centrifugation and then lyophilized for storage, toxicity tests and toxin extraction.

\subsection{Bioassays}

Mice weighing about $30 \mathrm{~g}$ were used to test the toxicity of the algae samples. The lyophilized Microcystis purified were first diluted in a small quantity of methnol and diluted with deionizd water as a vesicle. The dilution of $0.2 \mathrm{ml}$ volumes were injected i.p. into each of two mice. The 

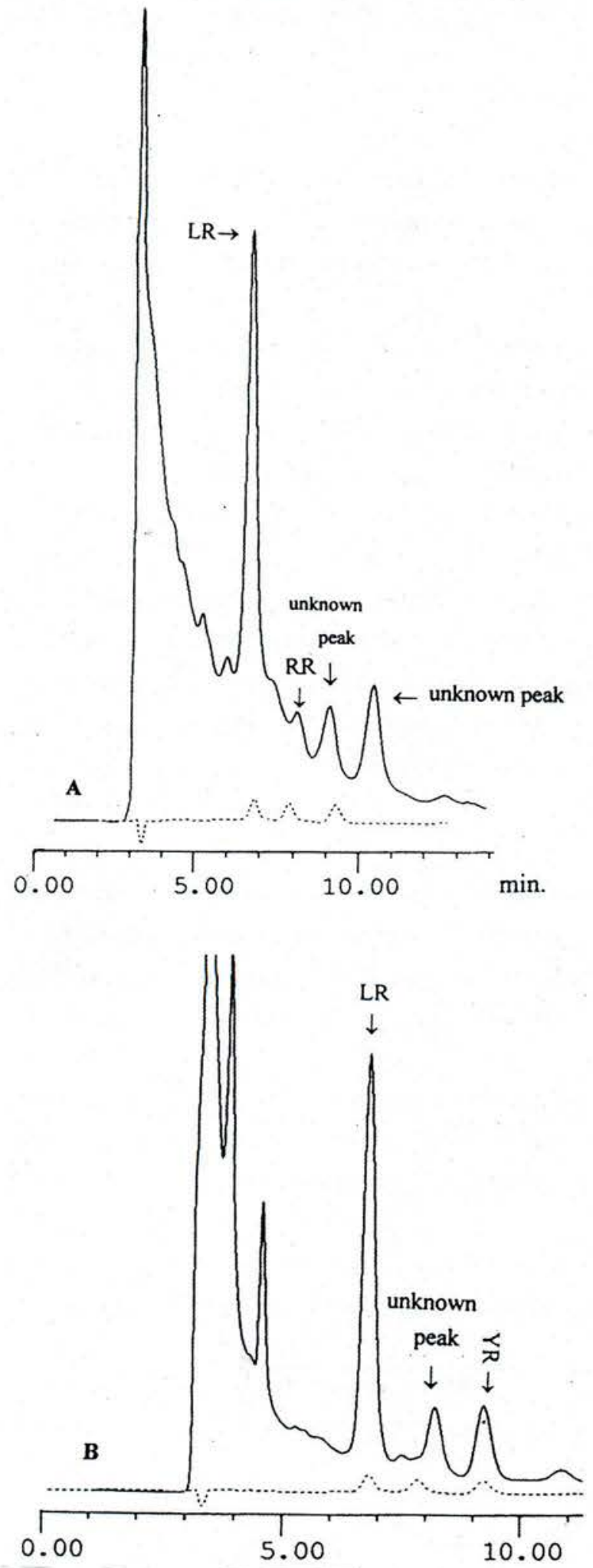

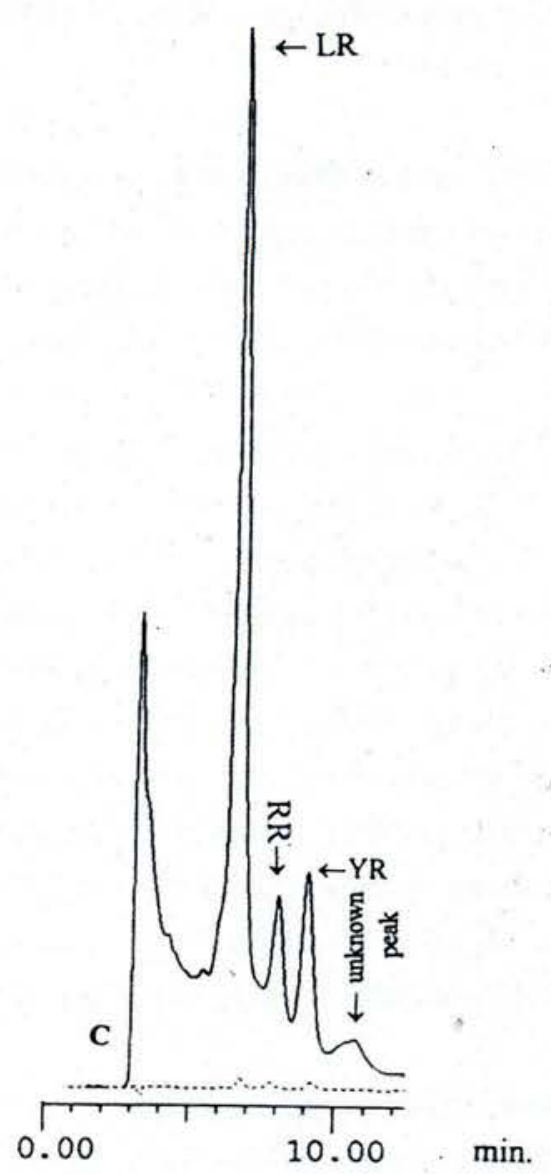

Fig. 1 The HPLC analysis results: The separation was accomplished under isocratic conditions with a mobil phase of $20 \mathrm{~mm}$ ammonium acetate, $\mathrm{pH} 5.0$, and acetonitrile (7:3) for $15 \mathrm{~min}$, followed by a gradient of 30 $\%-50 \%$ acetonitrile in water for 10 min. The volume injected was $1.0 \mathrm{ml}$ with UV detection at $238 \mathrm{~nm}$ and a flow raye of about $4.0 \mathrm{ml} \cdot \mathrm{min}^{-1}$.
A: Microcystis wesenbrergii
$\mathrm{B}: M$. viridis
C: $M$. aeruginosa

- standard; -----sample 
concentration of methonol in the dilutions were less than $1 \%$, which did not have a lethal effect on the animals.

\subsection{Toxin extraction and purification}

Lyophilized cells (1g) of the algae were extracted three times (1h) with 1-buanol: methanol: water $(1: 4: 15, \mathrm{v} / \mathrm{v})$ and cells debris was removed by centrifugation. The supernatants were combined and air-dried to $30 \%$ of the original volume. This material was passed through C-18 cartridges.

The C-18 cartridges (Bond Elut, USA) were first washed with water then eluted in sequenses with $20 \%, 80 \%$ and $100 \%$ methanol. The toxic fraction was eluted with $80 \%$ methanol. This fraction was filtered through a $0.45 \mu$ m nylon filter, the methanol removed by evaporation and the toxins seperated and purified by HPLC (high performance liquid chromatography).

The toxins were analyzed using a HPLC system equiped with a Gilson 206 pump and 811C stirring mixer with the analyzing colume (Rpp-250×4.6, Japan). The seperation was accomplished under isocratic conditions with a mobile phase of $20 \mathrm{mM}$ ammonium acetate, $\mathrm{pH} 5.0$, and acetonitrile (7:3) for $20 \mathrm{~min}$, followed by a gradient of $30-50 \%$ acetonitrile in water for $15 \mathrm{~min}$. The volume injected was $0.1 \mathrm{ml}$ with UV detection at $238 \mathrm{~nm}$ (Gilson 121 type UV detector) and a flow rate of of $1.0 \mathrm{ml} \cdot \mathrm{min}^{-1}$. All peakes were tested for toxicity by bioassay after evaporation of the mobile phase and resolubilization in $1.0 \mathrm{ml}$ of deionied water.

\section{Results and discussion}

Lyophilized cells of $M$. wesenbergii, $M$. viridis and $M$. aeruginosa and all peaks of HPLC analysis were tested for hepatotoxicity by the intraperitional mouse assay. The estimated $\mathrm{LD}_{50}$ of three lyophilized cell suspensions were $221 \mathrm{mg} \cdot \mathrm{kg}^{-1}, 188 \mathrm{mg} \cdot \mathrm{kg}^{-1}$ and $198 \mathrm{mg} \cdot \mathrm{kg}^{-1}$ respectively (Tab.1). Signs of poisoning were identical to those observed with other microcystins-producing toxic cyanobacteria.

The HPLC (high performance liquid chromatography) analysis results showed that all three Microcystis species contained microcystin LR. In addition, $M$. wesenbergii contained microcystin $\mathrm{RR}, M$. viridis contained microcystinYR, $M$. aeruginosa contained both microcystin RR and YR (Fig.1).

Tab. Composition of microcystins and toxicity of Microcystis blooms in different seasons in Dianchi Lake

\begin{tabular}{|c|c|c|c|c|c|c|}
\hline $\begin{array}{l}\text { Sam } \\
\text { ple }\end{array}$ & Season & Microcystis Isolate & $\begin{array}{c}\mathrm{LD}_{50} \\
\text { (mg.kg-1 mouse) }\end{array}$ & $\begin{array}{c}\text { Microcystin- } \\
\text { LR }\end{array}$ & $\begin{array}{c}\text { Microcystin- } \\
\text { YR }\end{array}$ & $\begin{array}{c}\text { Microcystin- } \\
\text { RR } \\
\end{array}$ \\
\hline A & Autumn & Microcystis wesenbergii & 221 & + & - & + \\
\hline B & Winter & M.viridis & 188 & + & + & - \\
\hline $\mathrm{C}$ & Summer & M.aeruginosa & 198 & + & + & + \\
\hline
\end{tabular}


On preparative HPLC, two unknown toxic peaks were obtained from $M$. wesenbergii, one unknown peak was obtained from both $M$. viridis and $M$. aeruginosa (Fig.1: A, B, C). The first peak from $M$. wesenbergii was detected under isocratic conditions after $9 \mathrm{~min}$ and the second was detected under gradient conditions after $10 \mathrm{~min}$ (Fig.1: A). Toxic one was further purified by analitical HPLC. Toxin two was sufficiently purified by the preparative HPLC.

The $\mathrm{LD}_{50}$ (i.p. mouse) of microcytin LR and RR were reported to be about 50 (Krishnamurthy, et al., 1986) and 600 (Watanabe, et al., 1988) $\mu \mathrm{g} \cdot \mathrm{kg}^{-1}$ respectively. In our experiment, the $\mathrm{LD}_{50}$ of the large toxic peaks (Fig.1) corresponding the standard microcystins LR were between 45 to 70 $\mu \mathrm{g} \cdot \mathrm{kg}^{-1}$, the microcystin RR were between 88 to $180 \mu \mathrm{g} \cdot \mathrm{kg}^{-1}$, and the microcystin YR in our experiment was about $160 \mu \mathrm{g} \cdot \mathrm{kg}^{-1}$.

All peaks were isolated and tested by bioassay. Three unknown peaks were found to be toxic to the mouse and the symbols were similar to other microcystins. But the characterizations of the toxins were not determined owing to the shortage of stardard microcystins. The toxins might need to be analyzed by structural determination methods such as amino acid analysis and NMR (nuclear magnetic resonance) techniques (Harada, et al., 1990).

The occurrence of toxic cyanobacteria that produce hepatotoxic microcystins in the Chinese fresh waters is more and more serious in recent years. Dianchi Lake is one of the largest freshwater lakes in south-eastern China which produces at least 100000 tons biomass (wet weight) of cyanobacteria per year (Zhao Yijun, et al., 1996). However, the toxin pollution in the lake has not aroused the official attention yet though the lake is the main source of drinking water for the 180 million residents of Kunming City. Our research has confirmed the toxic Microcystis occurred during the entire year (1995-1996) with the successions of dominating species of $M$. wesenbergii, $M$. vividis and $M$. aeruginosa. The findings suggest that it is necessary to monitor the occerrence of cyanobacteria blooms and their toxins in Chinese drinking water supplies. This will alert authorities to possible public healttı hazards from this potent hepatotoxic tumor promoters.

\section{Acknowledgements}

This study was supported by grants from National Sciences Foundation of China (number: 39600004). Chemical analysis was performed at Wuhan Institute of Virology, the Chinese Academy of Sciences.

\section{References}

Botes, D. P., Kruger, H., and Vilioen, C. C. 1982. Isolation and characterization four toxins from the blue-green alga Microcystis aeruginosa, Toxicon.20: 945-954.

Brooks, W. P., and Codd, G. A. 1986. Extraction and purification of toxic peptides from natural blooms and labora-tory isolates of the cyanobacterium Microcystis aeruginosa, Toxicon.20: 945-954.

Carmichael, W. W. 1988.Toxins of fresh water algae. In: Handbook of Natural Toxins, (Tu, A.T., ed.), New York: Marcel Dekker.3: 121-147 
Carmichael, W. W. 1992. Occurrence of toxic cyanobacteria. In: A Status report on Planktonic Cyanobacteria (Blue-green Algae) and their toxins, Cinlinati. OH: Environmental Monitoring Systems Laboratory, office of research and Development, U.S. Environmental Protection Agency. pp.15-26.

Carmichael, W.W., He. J-W., Eschedor, J., He, Z-R and Yu, M-J, 1988. Partial structure determination of hepatotoxic peptides from Microcystis aeruginosa (cyanobacteria) collected in ponds of Central China. Toxion.26:1213-1217.

Dierstein, R., Kaiseer, I., and Weckersser, J. 1988. Rapid determination of Microcystis sp. toxins by reversed phase liquid chromatography, FEMS Microbiol. Lett.49: 143-147.

Elleman, T. C., Falconer, I. R., Jackson, A. R. B., and Runneger, M. T. 1978. Isolation, characterization and pathology of the toxin from a Microcystis aeruginosa (Anacystis cyanca) bloom. Aust. J. Biol. Sci. 31: 209-218.

Harada, K. I., Ogwa, K., Kimura, Y., Murata, H., Suzuki. M. Thorn, P. M., Evans, W. R., et al. 1991. Microcystins from Anabaena flos-aquae NRC 525-17, Chem. Res. Toxicol.4: 535-540.

Harada, K. I., Ogawa, K., Matsuurs, K., Murata, H., Suzuki, M., Watanabe, M. F., Itezono, Y., and Nakayama, N. 1990. Structural determination of geometrical-isomers of microcystins-LR and -RR from cyanobacteria by two-dimensional NMR spectroscopic techniques, Chem. Res. Toxicol. 3: 473-481.

He Jiawan, Li Luoping, Zhao Yijun, and Liu Yongding. 1996. Preliminary studies on a Chiense new record of blue-green algae-Microcystis wesenbergii and its toxicity. Forth Asia-Pacific Congress on Animal, Plant and Microbial Toxins.

Krishnamurthy, T., Carmichael, W. W., and Sarver, E. R. 1986. Toxic peptides from freshwater cyanobacteria (blue-green algae). 1. Isolation, purification and characterization of peptides from Microcystis aeruginosa, Toxicon.24: 865-873.

Nishiwaki-Matsushima, R., Ohta, T., Nishiwaki, S., et al. 1992. Liver tumor promotion by the cyanobacterial cyclic peptide toxin microcystin-LR, J. Cancer Res. Clin. Oncol. 118:420-424.

Schwimmer, M., and Schwimmer, D. 1968. Medical aspects of phycology. In: Algae, Man and the Environment, (Jackson. D.F..ed.). New York: Syracuse University Press: 279-358

Sivonen, K., Skulberg, O.M., Namikoshi, M., Evans, W.R.., Carmichael, W. W., and Renehart, K. L. 1992.Two methyl ester derivatives of microcystins, Cyclic heptapeptide hepatotoxins, isolated from Anabaena flos-aquae strain cya 83/1, Toxicon. 30: 1465-1471.

Tsuji, K., Naito, S., Kondo, F., Watanabe, M. F., Suzuki, S., Nakazawa, H., Suzuki, M., Shimada, T., and Harada, K. 1994. A clean-up method for analysis of trace amounts of microcystins in lạke water, Toxicon. 32: 1251-1259.

Watanabe, M. F., Harada, K. I., Matsuura, K., Oishi, S., Watanabe, Y., et al. 1989. Heptapeptide toxins contained in natural samples of Microcystis species, Toxicity access 4:487-497.

Zhao Yijun, Li Luoping, and Liu Yongding. 1996. The comparision of phycobiliproteins between natural Microcystis and cultivated Spirulina, 1996 Symposium for Young Chinese Scientists on Ecology and Envolutionary Biology. 